\title{
Knowledge and Awareness About the Effect of Lemon Water Among Dental Students
}

\author{
Ashinie', R. Gayatri Devi ${ }^{2}$ and A. Jothi Priya ${ }^{3}$ \\ ${ }^{1}$ Graduate student Department of physiology Saveetha Dental College, Saveetha Institute of \\ Medical and Technical Sciences (SIMATS) Saveetha University, Chennai, India. \\ ${ }^{2}$ Assistant Professor Department of physiology Saveetha dental college, Saveetha Institute \\ of Medical and Technical Sciences (SIMATS) Saveetha University, Chennai, India. \\ ${ }^{3}$ Assistant Professor Department of physiology Saveetha dental college, Saveetha Institute \\ of Medical and Technical Sciences (SIMATS) Saveetha University, Chennai, India.
}

\section{ABSTRACT}

Lemon water is simply the juice of lemon mixed with water. Lemon water has become a popular morning beverage due to its excessive benefits and its properties. Lemon has antioxidant properties and it is usually consumed to reduce weight, maintaining skin tone and to optimise mood and memory. Over consumption of lemon water also has its own effect. The main aim of this study is to assess the awareness level on the effects of consumption of lemon water. A self administered questionnaire was prepared and distributed among 100 participants through an online survey. The study population included dental students. The data were then collected and analysed using SPSS and represented in pie charts and barcharts.Enamel erosion is the main effect of over consumption of lemon water. About 83\% of dental students were aware that the acidic nature of enamel causes tooth erosion due to over consumption. Majority of the dental students were aware of the effect of lemon water and its cause. This survey is evident that the dental students third year students were more aware of the effects of overconsumption of lemon water on teeth. The consumption of lemon water among them on a regular basis is also less.

KEY WORDS: LEMON WATER, ENAMEL EROSION, ACIDIC NATURE, DENTAL STUDENTS, AWARENESS.

\section{INTRODUCTION}

Lemon is an important medicinal plant of the family Rutaceae. It is cultivated mainly for its alkaloids which have anti cancer and anti bacterial potential (Dhanavade et al., 2011). Lemon water is simply the juice from lemon mixed with water. Lemon juice has many important properties like it has protective activity against

\section{ARTICLE INFORMATION}

*Corresponding Author: gayatri.physio88@gmail.com Received 29th July 2020 Accepted after revision 24th Sep 2020 Print ISSN: 0974-6455 Online ISSN: 2321-4007 CODEN: BBRCBA

Thomson Reuters ISI Web of Science Clarivate Analytics USA and Crossref Indexed Journal

\section{Clarivate
Analytics}

NAAS Journal Score 2020 (4.31) SJIF: 2020 (7.728)

A Society of Science and Nature Publication,

Bhopal India 2020. All rights reserved.

Online Contents Available at: http//www.bbrc.in/

Doi: $h t t p: / / d x$.doi.org/10.21786/bbrc/13.8/187 urolithiasis (Touhami et al., 2007). The lemon water blend also has an antioxidant potential (Gironés-Vilaplana et al., 2012). Apart from this lemon water consumption helps in reducing weight, maintaining skin tone and optimising mood and memory. Lemon and lime juice concentrates provide more citric acid per litre than any other citrus fruits (Penniston et al., 2008). These fruits with citric acid have erosive nature which affects the tooth surface especially enamel (Hooper et al., 2007). The erosive potential is also determined primarily by the ph and decrease in presence of salivary proteins. But overexposure of citric fruit water like lemon water on the tooth surface leads to monumental increase of enamel erosion (Jensdottir et al., 2006).

Earlier studies were made on the relationship between food habits and tooth erosion in Malaysian university students but this study mainly included acidic foods and

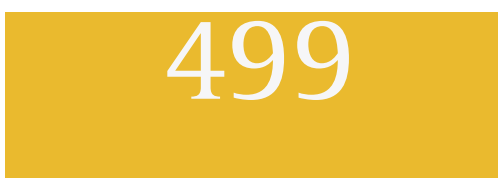


drinks (Manaf et al., 2012). Studies were also made on the dietary behaviour and awareness of dental erosion in adults in southern China to know whether they are aware of the causes of dental erosion (Chu, Pang and Lo, 2010). Studies on other citric fruit juices like orange juice was made which has less citric acid concentration than lemon. The orange juice significantly reduced surface hardness of enamel. The study confirms the erosive potential of acidic drinks people should be aware of (Wongkhantee et al., 2006). Study done by Ravi Gupta et al showed the attitude of students on drinking soft drinks which are also acidic like lemon water (Gupta et al., 2015). The results evident that the students showed early signs of erosion and caries and they are aware of the effects.

Most of the studies have analysed the awareness of people about the effect of soft drinks and other citrus fruit juices but they have not analysed lemon which has the highest citric acid content. Research was done to measure the clinical erosion due to single aetiology agents in a short period of time and confirmed the erosive potential of orange juice(West et al., 1998). There were no previous studies which analysed the erosive nature of lemon water specifically.

Previously our team had conducted numerous research (Choudhari and Jothipriya, 2016),(R and Sethu, 2018),(Fathima, 2016),(Shruthi and Preetha, 2018),(Renuka and Sethu, 2015), (Timothy, Gayatri Devi and Jothi Priya, 2019)survey based studies (Iyer, Gayatri Devi and Jothi Priya, 2019),(David et al., 2019),(Priya, Devi and Others, 2019),(Ilankizhai and Devi, 2016),(Swathy and Sethu, 2015) and review based studies (Dave and Preetha, 2016),(Baheerati and Gayatri Devi, 2018),(Samuel and Devi, 2015),(Harsha et al., 2015). Now we are focussing on epidemiological surveys. The idea for this survey stemmed from the current interest in our community. Thus the aim of the study is to assess the knowledge and awareness on lemon water among dental students.

\section{MATERIAL AND METHODS}

This is a cross sectional survey based study and a set of questionnaires was prepared based on knowledge and awareness about lemon water. It was circulated among dental students through an online survey planet software. The sample size chosen for the study was 100 . Before starting the survey a detailed explanation of study was shared to the participants. Once the participants completed filling the survey, the data was collected, compiled and arranged in a systematic manner and analysed in terms of frequencies in SPSS using chi square test. The confidence interval was found to be 95\% and statistical significance of $\mathrm{p}$ value $<0.05$.

\section{RESULTS AND DISCUSSION}

Enamel erosion is the main effect of over consumption of lemon water. Due to the acidic nature of lemon, the enamel starts to slowly erode and most of them are aware of this . From the responses about 70\% of them do not consume lemon water while only 30\% of them consume at morning or night (figure1). When they were asked about their frequency of consuming lemon water, $11 \%$ of them consume everyday, $27 \%$ of them consume once a week, 10\% of them consume everyday and 52\% of them do not consume regularly (figure 2). So most of them do not consume regularly which is good for their teeth. When they were asked why they think people drink lemon water, about 44\% said to lose weight , 22\% said they consume it as a health drink, 18\% said they consume due to vitamin c deficiency and about $16 \%$ said it improves skin tone (figure 3).

Figure 1: Pie chart depicting the response to the prevalence of drinking lemon water on a regular basis of the study participants, where blue represents yes and green represents no. Majority of $70 \%$ of the participants responded that they do not drink lemon water on a regular basis.

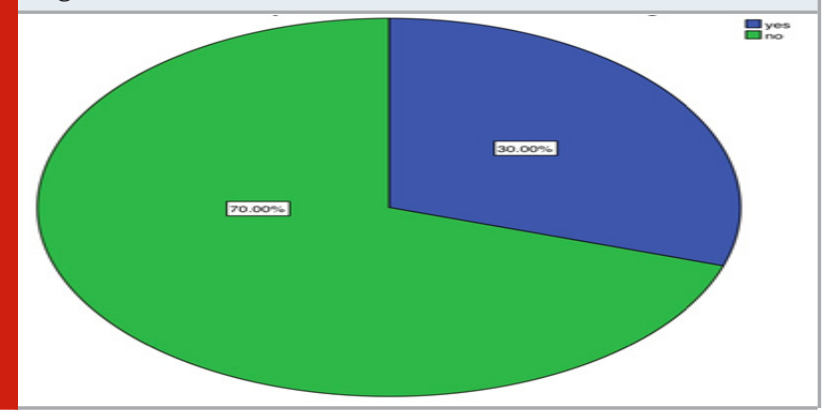

Figure 2: Pie chart depicting the response to the frequency of drinking lemon water of the study participants, where blue represents everyday, green represents once a week, beige represents thrice a week and purple represents not regularly. Majority of 52\% of the participants responded that they consume lemon water not regularly.

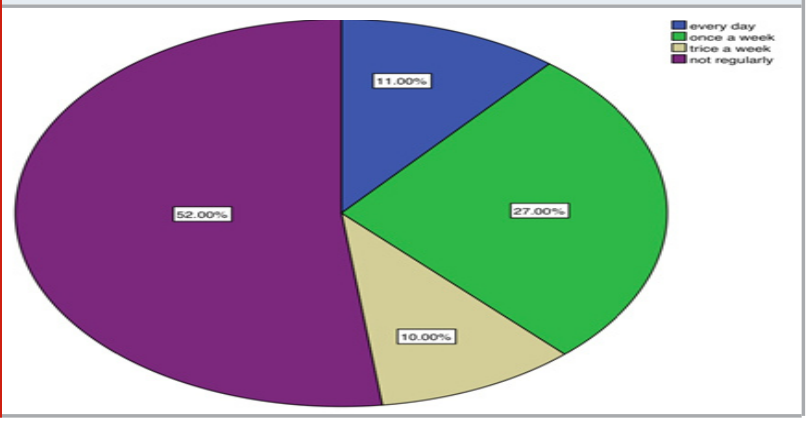

About $90 \%$ of the dental students are aware that the acidic nature of lemon affects the surface of the teeth (figure 4). About 83\% were also aware that the enamel of the teeth gets affected due to over consumption of lemon water (figure 5). About 83\% of the students were also aware that enamel erosion is the most common effect of overconsumption of lemon water (figure 6). When they were asked suggestions on how to prevent it about 43\% suggested to reduce consumption of lemon water and $43 \%$ suggested to drink it with a straw so that the teeth are not exposed to the acidity of lemon water and about 14\% suggested to stop drinking lemon water (figure 7). 
The association between the year of study of the study participants and their awareness on lemon water was done using chi square test. The association between year of study and awareness on the advantage of drinking lemon water was done using chi square test ( $\mathrm{p}$ value $=$ 0.001 ) which was statistically significant. Majority of first year students were aware of the advantages of lemon water (figure 8).

Figure 3: Pie chart depicting the response to the awareness on advantage of drinking lemon water of the study participants, where blue represents to lose weight, green represents as a health drink, beige represents to improve skin tone and purple represents not regularly. Majority of $44 \%$ of the participants responded that the main advantage of lemon water is that it helps in losing weight.

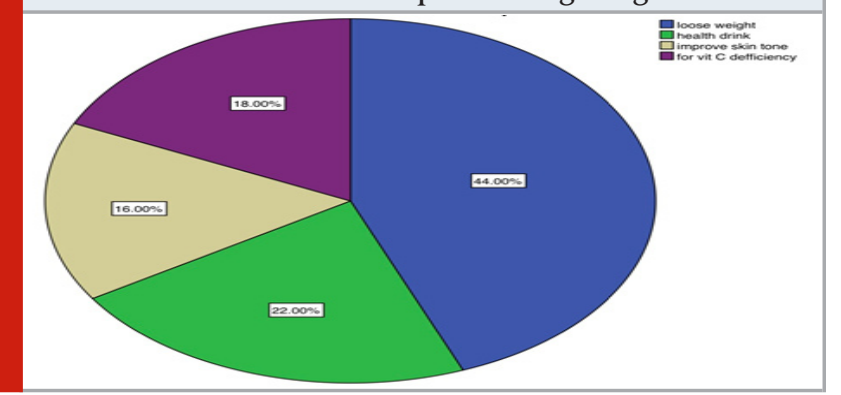

Figure 4: Pie chart depicting the response to the awareness on the nature of lemon water that affects the teeth of the study participants, where blue represents acidic and green represents alkaline. Majority of $90 \%$ of the participants responded that the acidic nature of lemon water affects the teeth surface.

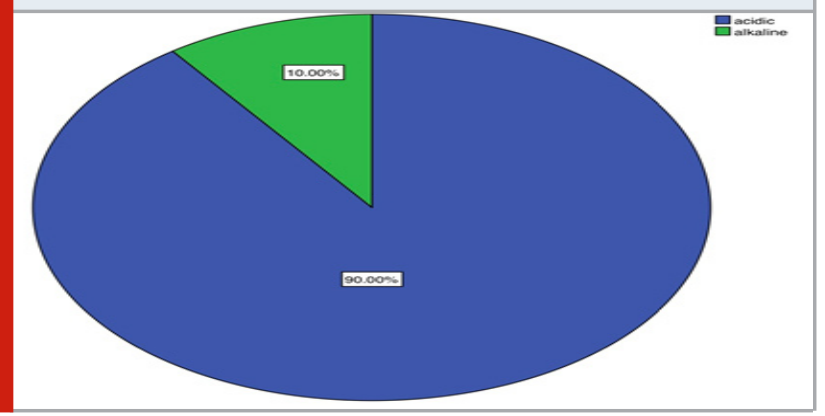

The association between year of study and awareness on the nature of lemon water that affects the teeth was done using chi square test ( $p$ value $=0.157$ ) which was statistically insignificant. Majority of third year students were aware of the nature of lemon water that affects the teeth (figure 9). The association between year of study and awareness on the part of teeth that gets affected due to over consumption of lemon water was done using chi square test ( $p$ value $=0.351$ ) which was statistically insignificant (figure 10). Majority of third year students were aware of the part of the teeth that gets affected due to over consumption of lemon water.

Previous studies were based on the awareness of children and adults about the enamel erosion, their effects and
Figure 5: Pie chart depicting the response to the awareness on the part of teeth that gets affected due to over consumption of lemon water of the study participants, where blue represents enamel, green represents dentine and beige represents pulp. Majority of $84 \%$ of the participants responded that the enamel gets affected due to over consumption of lemon water.

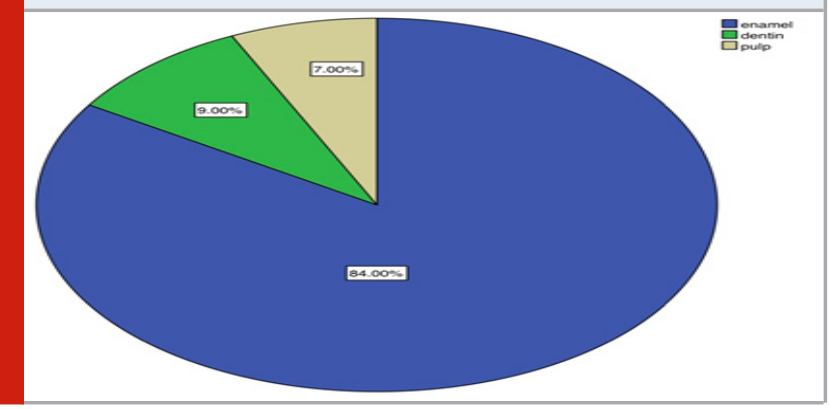

Figure 6: Pie chart depicting the response to the awareness on the effect on teeth due to over consumption of lemon water of the study participants, where blue represents enamel erosion, green represents plaque and beige represents caries. Majority of $85 \%$ of the participants responded that the enamel erosion is the important effect due to over consumption of lemon water.

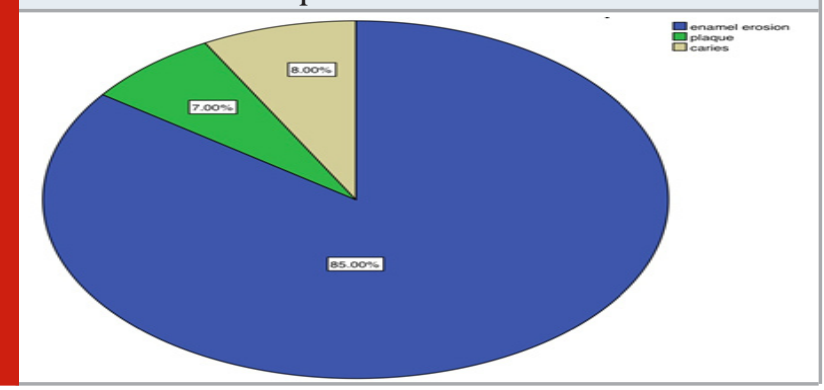

how to prevent it. These studies did not highlight the causes of enamel erosion. Most of the studies were based on the benefits of lemon as like examining the treated lemon for its feasibility of fluoride ion removal from aqueous environment (Tomar, Prasad and Kumar, 2014). Apart from $\mathrm{pH}$ of the food substances, chemical, behavioural and biological factors are also responsible for erosion (Lussi, Jaeggi and Zero, 2004). Studies have proved that overconsumption of citrus fruits is correlated to frequency of dental erosion (Künzel, Cruz and Fischer, 2000). The research studies were based on the effect of mixture of fruits with lemon in study regarding the effect of fruit infused water on blood glucose levels in young men (Ali et al., 2016).

Studies have also proved the decrease in surface hardness due to acidic juice (Ren, Amin and Malmstrom, 2009). These articles are not done specifically for lemon instead lemon was a component in the mixture of citrus fruits. The present study highlights the awareness specifically about lemon water and its effects among dental students. This study on awareness about lemon water among dental students is specifically about lemon water and 
its effect on tooth surface and to know how far dental students are aware of it. The important limitation of the study is that it is done on a small study population and is not done on a varied population instead it is restricted to only dental students. Further extensive studies on large and varied study populations can give us precise results about the awareness and knowledge on lemon water among people.

Figure 7: Pie chart depicting the response to the awareness on the ways to prevent enamel erosion due to consumption of lemon water of the study participants, where blue represents reduced consumption of lemon water, green represents use straw to drink and beige represents stop drinking lemon water. $43 \%$ of the participants responded to reduce the consumption of lemon water and $43 \%$ responded to use a straw to drink lemon water to prevent exposure of lemon water on teeth.

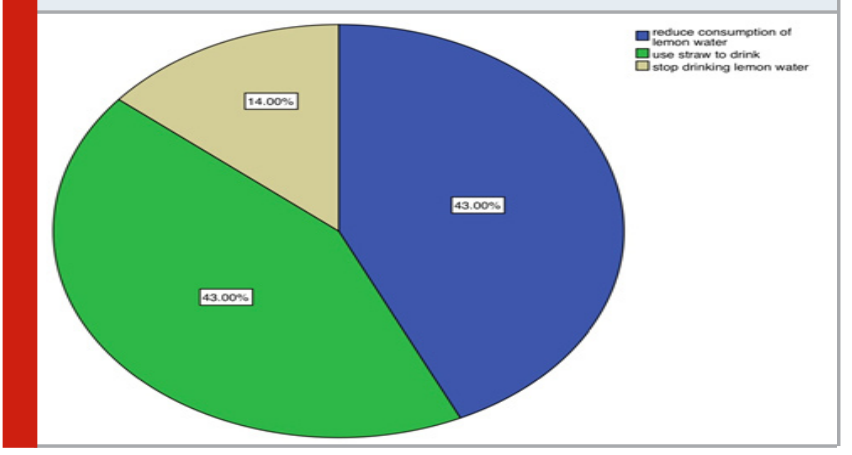

Figure 8: Bar chart representing the association between year of study and awareness on the advantage of drinking lemon water of the study participants, where blue represents to lose weight, green represents a health drink, beige represents improved skin tone and purple represents vitamin $C$ deficiency. $\mathrm{X}$ axis represents year of study and $\mathrm{Y}$ axis represents number of responses. The association between year of study and awareness on the advantage of drinking lemon water was done using chi square test ( $p$ value $=0.001$ ) which was statistically significant. Among 100 dental students, the majority of first year students were aware of the advantages of lemon water.

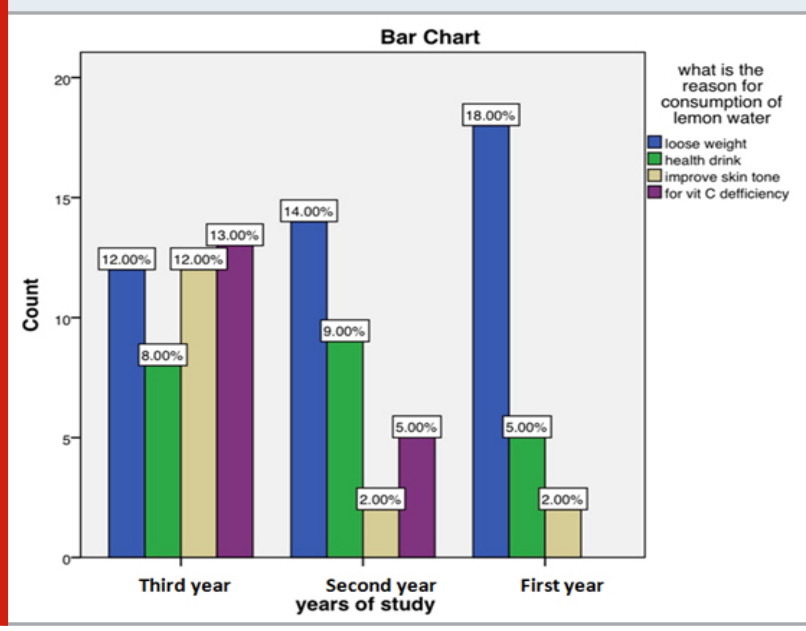

502
Figure 9: Bar chart representing the association between year of study and awareness on the nature of lemon water that affects the teeth of the study participants, where blue represents acidic and green represents alkaline. $\mathrm{X}$ axis represents year of study and $\mathrm{Y}$ axis represents number of responses. The association between year of study and awareness on the nature of lemon water that affects the teeth was done using chi square test ( $p$ value $=0.157$ ) which was statistically insignificant. Among 100 dental students, the majority of third year students were aware of the nature of lemon water that affects the teeth.

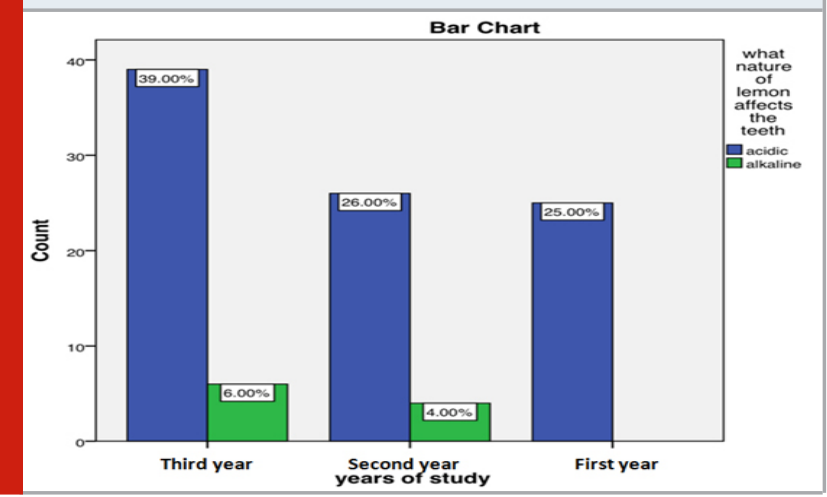

Figure 10: Bar chart representing the association between year of study and awareness on the part of teeth that gets affected due to over consumption of lemon water of the study participants, where blue represents enamel, green represents dentine and beige represents pulp. $\mathrm{X}$ axis represents year of study and $\mathrm{Y}$ axis represents number of responses. The association between year of study and awareness on the part of teeth that gets affected due to over consumption of lemon water was done using chi square test ( $p$ value $=0.351$ ) which was statistically insignificant. Among 100 dental students, the majority of third year students were aware of the part of the teeth that gets affected due to over consumption of lemon water.

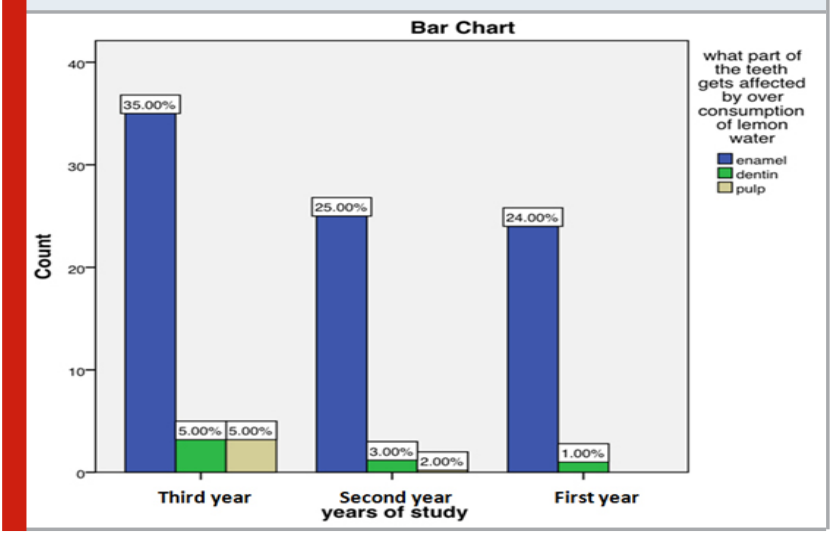

\section{CONCLUSION}

Enamel erosion is the common dental disease among this generation. Lemon water also serves as a cause for enamel erosion. From the survey it is clear that most of the students are not consuming lemon water on a regular 
basis . Those who are consuming are also aware of the effect of lemon water on tooth surfaces. The present study concludes that dental students have a proper knowledge and awareness of lemon water .

\section{ACKNOWLEDGEMENTS}

The author would like to thank the study participants for their participation and kind cooperation throughout the study

Conflict of Interest: The author declared that there was no conflict of interest in the present study.

\section{REFERENCES}

Ali, M. A. et al. (2016) 'Effect of Fruit-Infused Water (Combination of Apple, Banana and Lemon) on Blood Glucose in Young Men', Pakistan Journal of Nutrition, pp. 693-695. doi: 10.3923/pjn.2016.693.695.

Baheerati, M. M. and Gayatri Devi, R. (2018) 'Obesity in relation to Infertility', Research Journal of Pharmacy and Technology, p. 3183. doi: 10.5958/0974360x.2018.00585.1.

Choudhari, S. and Jothipriya, M. A. (2016) 'Nonalcoholic fatty liver disease', Journal of pharmacy research. indianjournals.com. Available at: http://www. indianjournals.com/ijor.aspx?target=ijor:rjptttvolume= 9ctissue $=10$ tarticle $=059$.

Chu, C. H., Pang, K. K. L. and Lo, E. C. M. (2010) 'Dietary behavior and knowledge of dental erosion among Chinese adults', BMC oral health, 10, p. 13.

Dave, P. H. and Preetha (2016) 'Pathogenesis and Novel Drug for Treatment of Asthma-A Review', Research Journal of Pharmacy and Technology, p. 1519. doi: 10.5958/0974-360x.2016.00297.3.

David et al. (2019) 'Physical Fitness among the Dental Physician, Dental Undergraduates and Postgraduates Students', Indian Journal of Public Health Research \&t Development, p. 223. doi: 10.5958/09765506.2019.02801.8.

Dhanavade, M. J. et al. (2011) 'Study antimicrobial activity of lemon (Citrus lemon L.) peel extract', British Journal of pharmacology and Toxicology, 2(3), pp. 119-122.

Fathima, F. (2016) 'Preetha. Evaluation of Thyroid Function Test in Obese Patients', Asian J Pharm Clin Res, 9(3), pp. 353-355.

Gironés-Vilaplana, A. et al. (2012) 'New beverages of lemon juice enriched with the exotic berries maqui, açaı冈, and blackthorn: bioactive components and in vitro biological properties', Journal of agricultural and food chemistry, 60(26), pp. 6571-6580.

Gupta, R. et al. (2015) 'A knowledge, attitude and practices of soft drinks among adolescent students and their dental health: A Questionnaire study', International Journal of Dental Health Concerns. Incessant Nature
Science Publishers Private Limited, 1(1), pp. 1-5. Harsha, L. et al. (2015) 'Systemic Approach to Management of Neonatal Jaundice and Prevention of Kernicterus', Research Journal of Pharmacy and Technology, p. 1087. doi: 10.5958/0974-360x.2015.00189.4.

Hooper, S. M. et al. (2007) 'The protective effects of toothpaste against erosion by orange juice: studies in situ and in vitro', Journal of dentistry, 35(6), pp. 476-481.

Ilankizhai, R. J. and Devi, G. (2016) 'Role of environmental factors on sleep patterns of different age groups: A survey-based study', Asian J Pharm Clin Res, 9, pp. 124-126.

Iyer, P. K., Gayatri Devi, R. and Jothi Priya, A. (2019) 'A Survey Study on Causes, Treatment and Prevention of Onychocryptosis', Indian Journal of Public Health Research \& Development, p. 807. doi: 10.5958/09765506.2019.01990.9.

Jensdottir, T. et al. (2006) 'Immediate erosive potential of cola drinks and orange juices', Journal of dental research, 85(3), pp. 226-230.

Künzel, W., Cruz, M. S. and Fischer, T. (2000) 'Dental erosion in Cuban children associated with excessive consumption of oranges', European journal of oral sciences, 108(2), pp. 104-109.

Lussi, A., Jaeggi, T. and Zero, D. (2004) 'The role of diet in the aetiology of dental erosion', Caries research, 38 Suppl 1, pp. 34-44.

Manaf, Z. A. et al. (2012) 'Relationship between food habits and tooth erosion occurrence in Malaysian University students', The Malaysian journal of medical sciences: MJMS, 19(2), pp. 56-66.

Penniston, K. L. et al. (2008) 'Quantitative assessment of citric acid in lemon juice, lime juice, and commerciallyavailable fruit juice products', Journal of endourology / Endourological Society, 22(3), pp. 567-570.

Priya, J., Devi, G. and Others (2019) 'Evaluation of Muscular Endurance among Dentists', Indian Journal of Public Health Research \& Development, 10(10).

Renuka, S. and Sethu, G. (2015) 'Regeneration after Myocardial Infarction', Research Journal of Pharmacy and Technology. A \& V Publications, 8(6), pp. 738741.

Ren, Y.-F., Amin, A. and Malmstrom, H. (2009) 'Effects of tooth whitening and orange juice on surface properties of dental enamel', Journal of dentistry, 37(6), pp. 424-431.

R, G. D. and Sethu, G. (2018) 'EVALUATION OF ADENOIDS BY ORONASAL AND NASAL SPIROMETRY', Asian Journal of Pharmaceutical and Clinical Research, p. 272. doi: 10.22159/ajpcr.2018.v11i10.27365.

Samuel, A. R. and Devi, M. G. (2015) 'Geographical distribution and occurrence of Endemic Goitre', Research Journal of Pharmacy and Technology. A \& V Publications, 8(8), pp. 973-978. 
Shruthi, M. and Preetha, S. (2018) 'Effect of Simple Tongue Exercises in Habitual Snorers', Research Journal of Pharmacy and Technology. A \& V Publications, 11(8), pp. 3614-3616.

Swathy, S. and Sethu, V. G. (2015) 'Acupuncture and lower back pain', Research Journal of Pharmacy and Technology. A \& V Publications, 8(8), pp. 991-993.

Timothy, C. N., Gayatri Devi, R. and Jothi Priya, A. (2019) 'Evaluation of Peak Expiratory Flow Rate (PEFR) in Pet Owners', Indian Journal of Public Health Research \&t Development, p. 803. doi: 10.5958/09765506.2019.01989.2.

Tomar, V., Prasad, S. and Kumar, D. (2014) 'Adsorptive removal of fluoride from aqueous media using Citrus limonum (lemon) leaf', Microchemical journal, devoted to the application of microtechniques in all branches of science, 112, pp. 97-103.

Touhami, M. et al. (2007) 'Lemon juice has protective activity in a rat urolithiasis model', BMC urology, 7, p. 18.

West, N. X. et al. (1998) 'A method to measure clinical erosion: the effect of orange juice consumption on erosion of enamel', Journal of dentistry, 26(4), pp. 329-335.

Wongkhantee, S. et al. (2006) 'Effect of acidic food and drinks on surface hardness of enamel, dentine, and tooth-coloured filling materials', Journal of dentistry, 34(3), pp. 214-220. 